in vivo $32: 1499-1504(2018)$

doi:10.21873/invivo.11406

\title{
Correlation Between Dosimetric Parameters and Acute Dermatitis of Post-operative Radiotherapy in Breast Cancer Patients
}

\author{
TADASHI TAKENAKA ${ }^{1}$, HIDEYA YAMAZAKI ${ }^{1}$, GEN SUZUKI $^{1}$, NORIHIRO AIBE ${ }^{1}$, \\ KOJI MASUI ${ }^{1}$, DAISUKE SHIMIZU ${ }^{1}$, TAKESHI NISHIMURA ${ }^{1}$, AKIHIRO NAKASHIMA ${ }^{1}$, \\ TOSHIYUKI OGATA ${ }^{1}$, KEIICHIRO MATSUSHITA $^{1}$, KEN YOSHIDA $^{2}$ and KEI YAMADA ${ }^{1}$ \\ ${ }^{1}$ Department of Radiology, Graduate School of Medical Science, \\ Kyoto Prefectural University of Medicine, Kyoto, Japan; \\ ${ }^{2}$ Department of Radiology, Osaka Medical College, Osaka, Japan
}

\begin{abstract}
Background/Aim: To examine the correlation between dosimetric parameters and acute radiation dermatitis in early breast cancer patients subjected to post-operative radiotherapy. Patients and Methods: The data of 84 patients treated with post-operative radiotherapy were analyzed. The total prescribed dose was 50 Gy in 25 fractions over 5 weeks. Radiation dermatitis was assessed according to Common Terminology Criteria for Adverse Events v4.0. We set organ at risk whole body (from neck to abdomen examined by CT images) also as surrogate skin volume (3 $\mathrm{mm}$ thickness). Results: A total of 28 patients showed radiation dermatitis grade equal or higher than 2 at the 50 Gy time point. These 28 patients were compared to 56 matched pair patients with grade 0-1 radiation dermatitis during the same treatment period. The mean of V5-20 and V40 in patient's whole volume and V40-50 in skin volume were significantly higher in patients who presented with acute radiation dermatitis Grades $\geq 2$ than in the other patients who did not. The statistically most significant difference was observed for V40 for skin volume and V5 for patient whole volume. Rate of acute radiation dermatitis grade $\geq 2$ was significantly higher for patients with V5 (whole body) $>1,360 \mathrm{~cm}^{3}$ than those with V5 (whole body) $<1,360 \mathrm{~cm}^{3}$ (47\% vs. 27\%, $\left.p=0.0353\right)$, as well as for patients with $V 40$ (skin volume) $>45 \mathrm{~cm}^{3}$ compared with
\end{abstract}

This article is freely accessible online.

Correspondence to: Tadashi Takenaka, Department of Radiology, Kyoto Prefectural University of Medicine, 465 Kajiicho, Kawaramachi Hirokoji, Kamigyo-ku, Kyoto 602-8566 Japan. Tel: +81 752515618, Fax: +81 752515840, e-mail: ttakenak@koto.kpum.ac.jp

Key Words: Breast cancer, post-operative radiotherapy, radiation dermatitis, dosimetric parameter. those with V40 (skin volume) $<45 \mathrm{~cm}^{3}(50 \%$ vs. $18 \%$, $p=0.0043$ ). Conclusion: Dosimetric parameters were useful to predict radiation dermatitis grade $\geq 2$. V5 (whole body) $1,360 \mathrm{~cm}^{3}$ and $V 40$ (skin volume) $45 \mathrm{~cm}^{3}$ may be dose volume constrain for radiation dermatitis grade $\geq 2$.

Breast-conservation therapy (BCT) for early-stage breast cancer, involving a lumpectomy followed by whole-breast radiotherapy, has become the standard therapy for suitable breast cancer patients $(1,2)$. Radiotherapy reduces local recurrence and improves overall survival rate compared to lumpectomy only (3). However, radiotherapy causes several treatment-related complications (e.g. dermatitis, pneumonitis, cardiac injuries), which sometimes deteriorate patients' quality of life $(1,2)$. Out of those toxicities, radiation dermatitis is the most common and extensively reported toxicity $(4,5)$. In a previous study, erythema occurred in more than $90 \%$ of the patients after standard radiotherapy, while $10 \%$ developed erythema of grade 3 or 4 in the 20th century (6). The influential factors for severe radiation dermatitis have been reported (714). High dose irradiation is one of the most important predictors of severity of both acute and late dermatitis and is associated with increased breast dose inhomogeneity and a resultant high irradiated volume (hot spots) $(8-11,14)$. As larger breasts, and higher body weight were reported to be predictive factors for radiation dermatitis, we included body mass index (BMI) in the factors examined in this study (8-11).

After spreading of three-dimensional conformal radiotherapy (3D-CRT), field in field technique (FIF) was installed to reduce hot spot $(15,16)$. FIF reduced hotspot more than $107-110 \%$ at the prescribed dose (53.5-55 Gy if prescribed dose is $50 \mathrm{~Gy}$ ), which may result in a reduction of severe radiation dermatitis. In addition, intensity modulated radiotherapy was also explored in order to reduce inhomogeneity and hotspot (17). 
Dose volume analysis is an essential part of radiation biology to predict outcome not only for tumor control but also for toxicity; i.e., V20 (normal lung volume irradiated by more than $20 \mathrm{~Gy}$ ) or mean lung dose is an important constrain to reduce radiation pneumonitis in lung irradiation (18), However, there is a paucity of literature on dosimetric parameters for radiation dermatitis (12). Therefore, in this study, the role of dosimetric parameters for the prediction of radiation dermatitis was explored. We set organ at risk the whole body because lower irradiation area also extended outside the treated volume. In addition, we set surrogate skin volume as a represented organ at risk for skin. This study's aim was to examine the predictive role of dosimetric parameter for radiation dermatitis in patients that underwent post-operative radiotherapy.

\section{Patients and Methods}

Patient characteristics. Between December 2008 and March 2016, 529 patients underwent postoperative radiation therapy at Department of Radiology Kyoto Prefectural Medical University. Of them, 28 patients $(5.3 \%)$ showed grade $\geq 2$ radiation dermatitis $(26$ grade 2 and 2 grade 3 ). These 28 patients were compared to 56 matched pair patients with grade $0-1$ radiation dermatitis during the same treatment period. To compare the influential factors for radiation dermatitis 56 matched pair (age, T, N, M, treatment periods) patients were included ( 2 patients with grade 0 and 54 patients with grade 1) (1:2 comparison). All patients had been traditionally treated with tangential Field's 6 MV photon beam using Linac. The median age of the patients was 54 years (range $=23-84$ years). Eligibility criteria were invasive or non-invasive ductal carcinoma, invasive lobular carcinoma, or malignant disease requiring post-operative radiotherapy, and ECOG (Eastern Cooperative Oncology Group) performance status 0-2. All patients had histologically proven breast malignancy. Table I shows the characteristics of patients. All patients were enrolled in the study after signing an informed consent prior to radiotherapy. The study followed the guidelines and protocol approved by the intrainstitutional ethics committee (IRB permission No. RBMR-c-803-2).

Treatment. Details of radiotherapy (RT) are described elsewhere (19). In brief, radiation dose was normalized to the point of the midplane of the breast (ICRU reference point). In all cases, $50 \mathrm{~Gy}$ was prescribed in 25 fractions. CT images for treatment planning were taken from the middle neck to the middle abdomen using $3 \mathrm{~mm}$ slices at the CT - scanner (Aquilion, Toshiba Medical, Tokyo, Japan). Radiotherapy planning and dosimetric parameters were calculated with a commercial treatment planning system (TPS) (XiO, Elekta Medical Systems Inc., Stockholm, Sweden). To obtain a uniform dose distribution, a wedge filter or FIF technique was used to reduce the maximum dose to $<110 \%$ of the prescribed dose $(15,19)$.

When FIF was applied, initially, the dose distribution was calculated using the tangential two field technique. Secondly, by viewing the dose distribution along the beam's-eye view, the subfields were optimally added to shield the areas of the breast receiving doses more than $107-110 \%$ of the prescription dose by manipulating the multi leaf collimators. The weight of additional subfields was approximately $6-10 \%$ of the total dose. All additional subfields were set not to shield the field isocenter as the dose reference point.
Dosimetric analysis. Whole body volume was delineated from neck to upper abdomen as solid organ on the CT images (Figure 1a). We set organ at risk whole body volume and also surrogate skin volume "skin volume". Skin volume was calculated by "whole body" minus "whole body minus $3 \mathrm{~mm}$ " volume in XiO (Figure 1b). The volumes of the "whole body" $\left(\mathrm{cm}^{3}\right)$ and "skin volume" $(\mathrm{cm} 3)$ receiving $5 \mathrm{~Gy}, 10 \mathrm{~Gy}, 20 \mathrm{~Gy}, 30 \mathrm{~Gy}, 40 \mathrm{~Gy}, 50 \mathrm{~Gy}, 107 \%$ of the prescribed dose $=53.5$ Gy (V5, V10, V20, V30, V40, V50, V107\%, respectively) and maximal dosage were calculated.

Toxicity analysis. Radiation oncologists performed an assessment of radiation dermatitis according to the Common Terminology Criteria for Adverse Events (CTCAE) version 4 at 50 Gy point. Comparisons between patients with radiation dermatitis grade 2-3 and grade $0-1$ were made.

Statistical analysis. All statistical analyses were carried out with the Statview-v5.0 software program. Student's $t$-tests were used for normally distributed data and the Mann-Whitney $U$-test for skewed data. For analyzing correlation coefficients $|r|$, we defined $p<0.05$ if $|r| \geq 0.2(0.4 \geq|r|>0.2$; weak correlation, $0.7 \geq|r|>0.4$; intermediate correlation, $|r|>0.7$; strong correlation). The chi-square test was used to analyze percentages and considered a $p$-value of $<0.05$ as statistically significant.

\section{Results}

There were no background differences in patients with grade $0-1$ and grade $2-3$ of radiation dermatitis. No toxicity of grade $4 \geq$ was detected in any patient.

Table II shows the correlations between the dosimetry parameters (whole body) and radiation dermatitis grade $\geq 2$. V5, V10, V20, and V40 showed statistically significant differences in patients' whole body. The lowest $p$-value was observed for V5 ( $p=0.011$, Figure 2a).

Table III shows the correlations between the dosimetric parameter (skin volume) and radiation dermatitis grade $\geq 2$. Patients with grade $\geq 2$ dermatitis had significantly higher values in V40 and V50 (skin volume). The lowest p-value was observed for skin V40 ( $p=0.008$, Figure 2b).

V5 (whole body) and V40 (skin volume) were statistically significantly correlated with BMI $(p=0.0171,|r|=0.260$, $p=0.0141,|r|=0.444$, Table IV).

Rate of acute radiation dermatitis grade $\geq 2$ was significantly higher for patients with V5 (whole body) $>1360$ $\mathrm{cm} 3$ than those with V5 (whole body) $\leq 1360 \mathrm{~cm}^{3}$ (47\% vs. $23 \%, p=0.0353$ ), as well as for patients with V40 (skin volume) $>45 \mathrm{~cm}^{3}$ compared with those with V40 (skin volume $) \leq 45 \mathrm{~cm}^{3}$ (50\% vs. $18 \%, p=0.0043$, Table V).

\section{Discussion}

Breast conserving therapy has become a standard treatment as it helps to improve QOL of breast cancer patients. Activities of daily living, physical factors, and psy $\neg$ chological status are the main criteria in assessing QOL 
a

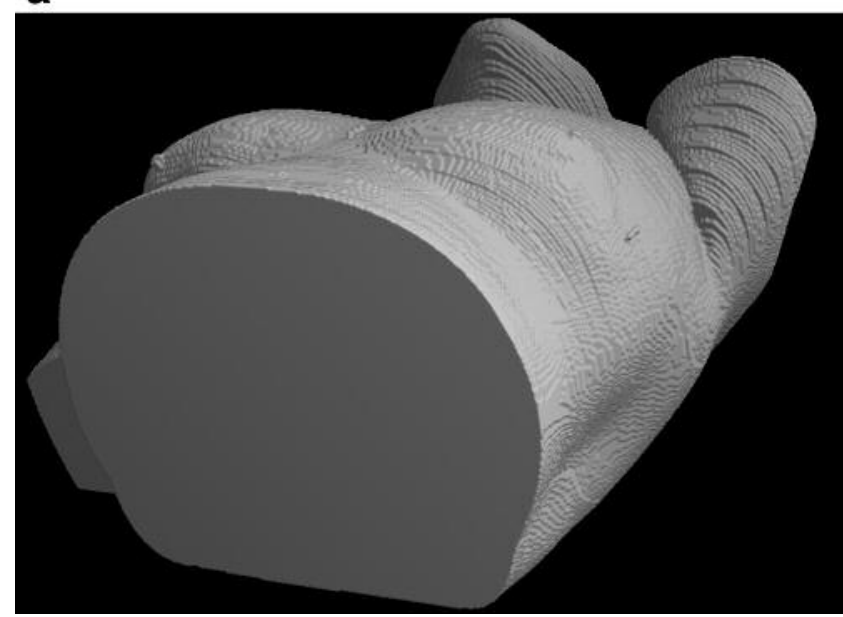

b

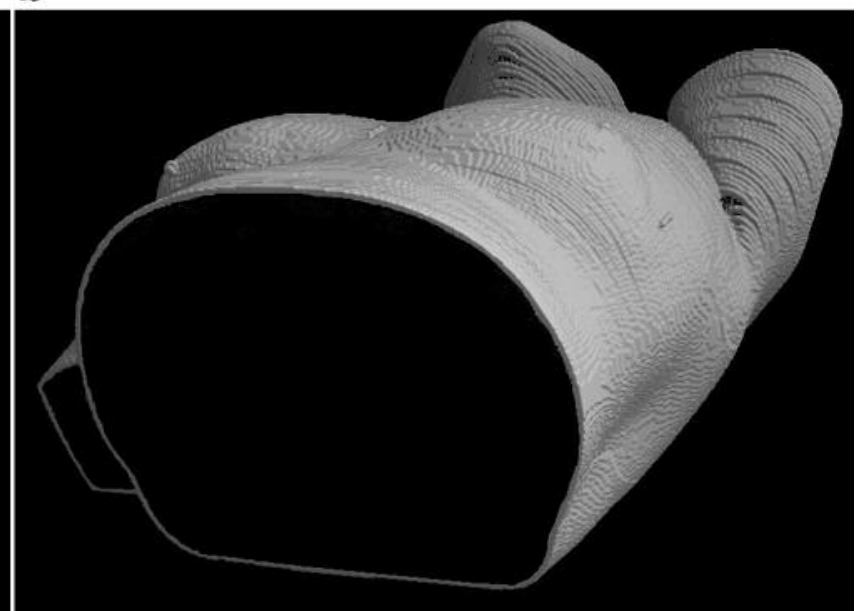

Figure 1. Represented figures of organs at risk. a) Whole body. Whole body of patient was created by contour of patient's outline. b) Skin volume. Skin volume (3 mm thickness) was calculated by "whole body" (Figure 1a) minus "whole body minus 3 mm" volume.

Table I. Characteristics and treatment factors of patients.

\begin{tabular}{|c|c|c|c|c|c|c|c|c|}
\hline \multirow[t]{2}{*}{ Variables } & \multirow[t]{2}{*}{ Strata } & \multicolumn{2}{|l|}{$\begin{array}{c}\text { All } \\
\mathrm{n}=84\end{array}$} & \multicolumn{2}{|l|}{$\begin{array}{c}\text { Grade } 0-1 \\
n=56\end{array}$} & \multicolumn{2}{|l|}{$\begin{array}{c}\text { Grade } 2-3 \\
n=28\end{array}$} & \multirow[t]{2}{*}{$p$-Value } \\
\hline & & $\begin{array}{l}\text { No. or Median } \\
\text { (range) }\end{array}$ & $(\%)$ & $\begin{array}{l}\text { No. or Median } \\
\quad \text { (range) }\end{array}$ & $(\%)$ & $\begin{array}{l}\text { No. or Median } \\
\quad \text { (range) }\end{array}$ & $(\%)$ & \\
\hline Age & & $54(23-77)$ & & $56(26-77)$ & & $48(23-73)$ & & \\
\hline \multirow[t]{2}{*}{ Primary site } & Right & 37 & $(44 \%)$ & 23 & $(41 \%)$ & 14 & $(50 \%)$ & 0.5865 \\
\hline & Left & 47 & $(56 \%)$ & 33 & $(59 \%)$ & 14 & $(50 \%)$ & \\
\hline \multirow[t]{3}{*}{ Histology } & Invasive Dactal Ca. & 57 & $(68 \%)$ & 39 & $(70 \%)$ & 18 & $(64 \%)$ & 0.7596 \\
\hline & DCIS & 23 & $(27 \%)$ & 14 & $(25 \%)$ & 9 & $(32 \%)$ & \\
\hline & Other & 4 & $(5 \%)$ & 3 & $(5 \%)$ & 1 & $(4 \%)$ & \\
\hline \multirow[t]{7}{*}{ pT category } & is & 18 & $(21 \%)$ & 12 & $(21 \%)$ & 6 & $(21 \%)$ & 0.5667 \\
\hline & 0 & 3 & $(4 \%)$ & 2 & $(4 \%)$ & 0 & $(0 \%)$ & \\
\hline & 1 & 44 & $(52 \%)$ & 27 & $(48 \%)$ & 17 & $(61 \%)$ & \\
\hline & 2 & 15 & $(18 \%)$ & 11 & $(20 \%)$ & 4 & $(14 \%)$ & \\
\hline & 3 & 2 & $(2 \%)$ & 2 & $(4 \%)$ & 0 & $(0 \%)$ & \\
\hline & 4 & 1 & $(1 \%)$ & 2 & $(4 \%)$ & 0 & $(0 \%)$ & \\
\hline & Other & 1 & $(1 \%)$ & 0 & $(0 \%)$ & 1 & $(4 \%)$ & \\
\hline Body mass index & $\left(\mathrm{kg} / \mathrm{m}^{2}\right)$ & $21.5(15.9-38.9)$ & & $21.4(15.9-30.0)$ & & $21.4(16.3-38.9)$ & & 0.8199 \\
\hline
\end{tabular}

DCIS: Ductal carcinoma in situ.

(19) and cosmetic assessment is one of the factors of interest to women. Radiation-induced skin changes were recognized soon after the discovery of x-rays and were scientifically reported as early as in 1902 (5). This is a consequence of the well-known fact that sensitivity to radiation varies between individuals and underlines the necessity of finding an objective and predictive assessment method. Therefore, we made a dose volume analysis in skin volume to find useful objective parameters to predict severe radiation dermatitis.
Several influential factors have been reported for radiation dermatitis. Larger breast volume, lower radiotherapy energy, larger irradiated volume, boost irradiation, and absence of skin care elevated severe radiation dermatitis (8-14). Inhomogeneity of radiation dose distribution also caused severe radiation dermatitis. With conventional breast radiotherapy, a portion of the breast tissue receives $110 \%$ of the prescription dose, occasionally up to $120 \%$ (20). Chen et al. reported that such hotspot with over $110 \%$ of the 
Table II. Correaltions between dosimetric parameters of whole body and radiation dermatitis grade 2 or more.

\begin{tabular}{llccc}
\hline Variables & & $\begin{array}{c}\text { Grade 0-1 } \\
(\mathrm{n}=56) \\
\text { Mean } \pm \text { SD }\end{array}$ & $\begin{array}{c}\text { Grade 2-3 } \\
(\mathrm{n}=28) \\
\text { Mean } \pm \text { SD }\end{array}$ & $p$-Value \\
\hline V5 & $\left(\mathrm{cm}^{3}\right)$ & $1412 \pm 531$ & $1645 \pm 475$ & $\mathbf{0 . 0 1 1}$ \\
V10 & $\left(\mathrm{cm}^{3}\right)$ & $1263 \pm 482$ & $1458 \pm 437$ & $\mathbf{0 . 0 2 7}$ \\
V20 & $\left(\mathrm{cm}^{3}\right)$ & $1096 \pm 437$ & $1266 \pm 403$ & $\mathbf{0 . 0 3 5}$ \\
V30 & $\left(\mathrm{cm}^{3}\right)$ & $968 \pm 398$ & $1123 \pm 378$ & 0.107 \\
V40 & $\left(\mathrm{cm}^{3}\right)$ & $804 \pm 346$ & $936 \pm 347$ & $\mathbf{0 . 0 4 0}$ \\
V50 & $\left(\mathrm{cm}^{3}\right)$ & $248 \pm 185$ & $320 \pm 231$ & 0.100 \\
V107 \% & $\left(\mathrm{cm}^{3}\right)$ & $4.12 \pm 11$ & $23 \pm 76$ & 0.145 \\
Maximal dosage & $\left(\mathrm{Gy}^{3}\right.$ & $53.76 \pm 0.88$ & $54.18 \pm 1.11$ & 0.154 \\
\hline
\end{tabular}

Bold depicted statistically significant values.

Table III. Correaltions between dosimetric parameters of skin volume and radiation dermatitis grade 2 or more.

\begin{tabular}{llccc}
\hline Variables & & $\begin{array}{c}\text { Grade } 0-1 \\
(\mathrm{n}=56) \\
\text { Mean } \pm \text { SD }\end{array}$ & $\begin{array}{c}\text { Grade 2-3 } \\
(\mathrm{n}=28) \\
\text { Mean } \pm \text { SD }\end{array}$ & $p$-Value \\
\hline V5 & $\left(\mathrm{cm}^{3}\right)$ & $162.7 \pm 29.2$ & $167.6 \pm 29.8$ & 0.471 \\
V10 & $\left(\mathrm{cm}^{3}\right)$ & $152.1 \pm 27.8$ & $156.9 \pm 26.9$ & 0.488 \\
V20 & $\left(\mathrm{cm}^{3}\right)$ & $135.7 \pm 25.1$ & $140.0 \pm 22.7$ & 0.471 \\
V30 & $\left(\mathrm{cm}^{3}\right)$ & $103.9 \pm 20.0$ & $111.4 \pm 18.6$ & 0.107 \\
V40 & $\left(\mathrm{cm}^{3}\right)$ & $43.8 \pm 11.7$ & $51.4 \pm 12.7$ & $\mathbf{0 . 0 0 8}$ \\
V50 & $\left(\mathrm{cm}^{3}\right)$ & $0.9 \pm 1.4$ & $1.6 \pm 2.1$ & $\mathbf{0 . 0 4 9}$ \\
V107 \% & $\left(\mathrm{cm}^{3}\right)$ & $0.02 \pm 0.1$ & $0.03 \pm 0.1$ & 0.195 \\
Maximal dosage & $\left(\mathrm{Gy}^{3}\right.$ & $52.42 \pm 1.08$ & $53.00 \pm 1.37$ & 0.135 \\
\hline
\end{tabular}

Bold depicted statistically significant values.

prescribed dose may be an important predictor for radiation dermatitis (12). In addition, smoking, absence of allergies, use of chemotherapy were also reported to be potential influential factors for radiation dermatitis $(10,11)$.

Erythema after standard 3D-CRT was observed at an average of $90 \%$ of the patients, while $10 \%$ developed erythema grade 3 or 4 (6). However, recent breast cancer treatment includes several chemotherapy agents, antihormonal therapies and improved radiation therapy techniques. Kraus-Tiefenbacher et al. reported lower skin toxicity rate of $70 \%$ erythema [Grade $1(62.2 \%)$, grade 2 $(8.5 \%)$, and no grade 3 ] in 211 patients with careful skin care (11). Also, in a previous study, we found that around $30 \%$ of patients developed grade $\geq 2$ radiation dermatitis using two-dimensional planning and 3D-CRT wedge technique (19). On contrast, only less than $5 \%$ of grade $\geq 2$ radiation dermatitis was found in the present study after installing FIF technique. Nakamura et al. also reported that FIF technique offered excellent target coverage and homogeneity (16).
Table IV. Correlations among influencial factors on radiation dermatitis grade 2 or more and body mass index.

\begin{tabular}{lllll}
\hline Variables & \multicolumn{1}{l}{$\begin{array}{c}\text { V5 } \\
\text { (whole } \\
\text { body) }\end{array}$} & $\begin{array}{c}\text { V40 } \\
\text { (skin } \\
\text { volume) }\end{array}$ & $\begin{array}{c}\text { Body } \\
\text { mass } \\
\text { index }\end{array}$ \\
\hline & & & & \\
V5 (whole body) & $\left(\mathrm{cm}^{3}\right)$ & & $<0.0001$ & 0.0171 \\
V40 (skin volume) & $\begin{array}{l}\left(\mathrm{cm}^{3}\right) \\
\left(\mathrm{kg} / \mathrm{m}^{2}\right)\end{array}$ & 0.611 & & 0.0141 \\
Body mass index & 0.260 & 0.444 & \\
\hline
\end{tabular}

$p$-Value depicted in upper right columns, and |r| value depicted in lower left columns. Bold depicted statistically significant values.

Table V. Correlation between dosimetric parameter and radiation dermatitis grade 2 or more.

\begin{tabular}{|c|c|c|c|c|c|c|}
\hline \multirow[t]{2}{*}{ Variables } & \multirow[t]{2}{*}{ Strata } & \multicolumn{2}{|c|}{$\begin{array}{c}\text { Grade } 0-1 \\
n=56\end{array}$} & \multicolumn{2}{|c|}{$\begin{array}{c}\text { Grade } 2-3 \\
n=28\end{array}$} & \multirow[t]{2}{*}{$p$-Value } \\
\hline & & No. & $(\%)$ & No. & $(\%)$ & \\
\hline \multirow{2}{*}{$\begin{array}{l}\text { V5 } \\
\text { (Whole body) }\end{array}$} & $-1360 \mathrm{~cm}^{3}$ & 37 & $(77 \%)$ & 11 & $(23 \%)$ & 0.0353 \\
\hline & $1360 \mathrm{~cm}^{3}-$ & 19 & $(53 \%)$ & 17 & $(47 \%)$ & \\
\hline \multirow{2}{*}{$\begin{array}{l}\text { V40 } \\
\text { (Skin volume) }\end{array}$} & $-45 \mathrm{~cm}^{3}$ & 36 & $(82 \%)$ & 8 & $(18 \%)$ & 0.0043 \\
\hline & $45 \mathrm{~cm}^{3}-$ & 20 & $(50 \%)$ & 20 & $(50 \%)$ & \\
\hline
\end{tabular}

Bold depicted statistically significant values.

Sasaoka et al. reported that FIF significantly reduced Radiation Therapy Oncology Group (RTOG) grade 2 acute skin toxicity compared with the tangential field technique (3.1 vs. $10.6 \%$ ) which concurred to our data (15). This could be due, in part, to the fact that Japanese women have smaller breasts than Caucasian women, which results in decreased irradiated volume and toxicity. Ding et al. also reported lower rate of grade 2 toxicity (grade $1=68.9 \%$, grade $2=11 \%$ ), in the Chinese population (9).

This is the first report analyzing dosimetric parameters for radiation dermatitis using organs at risk "whole body" and "skin volume". Chen et al. reported that TV-V110\% > 5.13\% (percent volume receiving $110 \%$ of prescribed dose within treated volume (TV)) may be an important predictor for radiation induced dermatitis and $\mathrm{TV}-\mathrm{V} 110 \%$ related to the location of moist desquamation (12). Treated volume was considered the volume enclosed within the prescribed dose and radiation hot spot the areas receiving excessive dose, especially $>110 \%$ of the prescribed dose. We agree that 

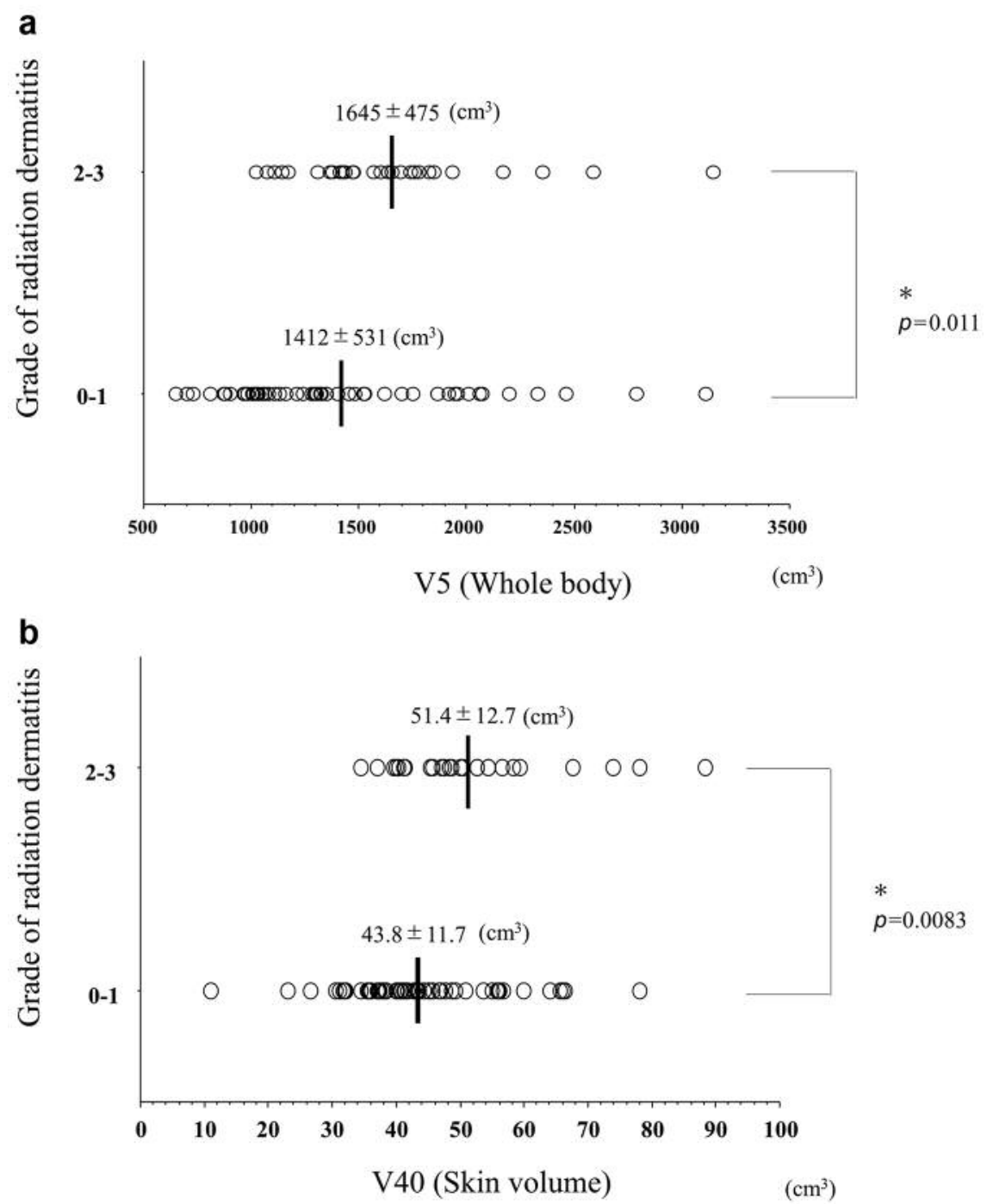

Figure 2. Correlations between dosimetric parameters and radiation dermatitis. a) V5 (whole body), b) V40 (skin volume).

hotspot is an important factor for prediction of radiation dermatitis. However, with the introduction of FIF technique, the subfields are added to the main section, hotspots were reduced at $110 \%$ of prescribed dose or more. Therefore, we thought that "whole body" or "skin volume" estimation could be useful for assessment of skin toxicity because irradiated area may spread outside breast volume or treated volume in radiotherapy planning. In fact, lowest dose constrain V5 revealed significant for radiation dermatitis. Then, treatment volume is not restricted within the organ at risk requiring larger volume. At present, no consensus on organ at risk for assessment of dermatitis has reached. This issue (optimal organ at risk for radiation dermatitis) could be left for further investigation. Actually, until now, larger breast has been identified as an important predictor of radiation dermatitis (8-
14). Also, in this study, V5 (whole body) and V40 (skin volume) showed strong correlations to body mass index. However, BMI was not found to be significant for radiation dermatitis. Which implies that FIF technique could reduce the significance of $\mathrm{V} 110 \%$ and BMI for prediction of radiation dermatitis by diminishing the hotspot.

Our study had several limitations. First, this was a preliminary study with a small number of patients. Next, our data did not contain the subjective evaluation of symptoms by the patients, which would be important because several studies found significant differences between patients and clinicians when assessing toxicities following radiotherapy or chemotherapy $(21,22)$. At last, it does not contain the analysis on maximal color alteration which could occur even after completion of radiotherapy. In a Canadian prospective 
trial, Drost et al. reported that ratio of grade $\geq 2$ dermatitis peaked at 2 weeks after completion radiotherapy at $61.9 \%$, which is higher than $36.3 \%$ (Grade $2=38.5 \%$, grade $3=4.5 \%$ ) at the 50 Gy timing (9). Therefore, rate of grade $\geq 2$ dermatitis varies according to timing of assessment.

In conclusion, our present data showed that dosimetric parameters were useful to predict radiation dermatitis grade $\geq 2$. V5 (whole body) $1,360 \mathrm{~cm}^{3}$ and V40 (skin volume) $45 \mathrm{~cm}^{3}$ may be dose volume constrains for radiation dermatitis grade $\geq 2$.

\section{Conflicts of Interest}

The Authors state no conflicts of interest regarding this study.

\section{References}

1 Fisher B, Anderson S, Bryant J, Margolese RG, Deutsch M, Fisher ER, Jeong JH and Wolmark N: Twenty-year follow-up of a randomized trial comparing total mastectomy, lumpectomy, and lumpectomy plus irradiation for the treatment of invasive breast cancer. N Engl J Med 347: 1233-1241, 2002.

2 Clarke M, Collins R, Darby S, Davies C, Elphinstone P, Evans V, Godwin J, Gray R, Hicks C, James S, MacKinnon E, McGale P, McHugh T, Peto R, Taylor C, Wang Y and Early Breast Cancer Trialists Collaborative Group: Effects of radiotherapy and of differences in the extent of surgery for early breast cancer on local recurrence and 15-year survival: an overview of the randomized trials. Lancet 366: 2087-2106, 2005.

3 Whelan TJ, Julian J, Wright J, Jadad AR and Levine ML: Does locoregional radiation therapy improve survival in breast cancer? A meta-analysis. J Clin Oncol 18: 1220-1229, 2000.

4 Hymes SR, Strom EA and Fife C: Radiation dermatitis: clinical presentation, pathophysiology, and treatment 2006. J Am Acad Dermatol 54: 28-46, 2006.

5 Frieben H: Demonstration eines Cancroid des rechten Handruckens, das sich nach langdauernder Einwirkung von Rontgenstrahlen entwickelt hatte. Fortschr Rontgenstr 6: 106-111, 1902.

6 López E1, Núñez MI, Guerrero MR, del Moral R, de Dios Luna J, del Mar Rodríguez M, Valenzuela MT, Villalobos M and Ruiz de Almodóvar J: Breast cancer acute radiotherapy morbidity evaluated by different scoring systems. Breast Canc Res Treat 73: 127-134, 2002.

7 Fisher J1, Scott C, Stevens R, Marconi B, Champion L, Freedman GM, Asrari F, Pilepich MV, Gagnon JD and Wong G: Randomized phase III study comparing Best Supportive Care to Biafine as a prophylactic agent for radiation-induced skin toxicity for women undergoing breast irradiation: Radiation Therapy Oncology Group (RTOG) 97-13. Int J Radiat Oncol Biol Phys 48: 1307-1310, 2000.

8 Fernando IN, Ford HT, Powles TJ, Ashley S, Glees JP, Torr M, Grafton D and Harmer CL: Factors affecting acute skin toxicity in patients having breast irradiation after conservative surgery: a prospective study of treatment practice at the Royal Marsden Hospital. Clin Oncol (R Coll Radiol) 8: 226-233, 1996.

9 Drost L, Li N, Vesprini D, Sangha A, Lee J, Leung E, Rakovitch E, Yee C, Chow E, and Ruschin M: Prospective study of breast radiation dermatitis. Clin Breast Cancer, 2018. doi: 10.1016/j.clbc.2018.03.008. [Epub ahead of print]
10 Ding J, Guo Y, Li Q, Chen J, Hu P, Liu Q, Cao Y and Wu J: The incidence of postoperative radiotherapy-induced acute dermatitis in breast cancer and its influencing factors for Chinese women. Onco Targets Ther 11: 1665-1670, 2018.

11 Kraus-Tiefenbacher U, Sfintizky A, Welzel G, Simeonova A, Sperk E, Siebenlist K, Mai S and Wenz F: Factors of influence on acute skin toxicity of breast cancer patients treated with standard three-dimensional conformal radiotherapy (3D-CRT) dafter breast conserving surgery (BCS). Radiat Oncol 7: 217, 2012.

12 Chen MF, Chen WC, Lai CH, Hung $\mathrm{CH}$, Liu $\mathrm{KC}$ and Cheng $\mathrm{YH}$ : Predictive factors of radiation-induced skin toxicity in breast cancer patients. BMC Cancer 10: 508, 2010.

13 Yamazaki H, Yoshida K, Kotsuma T, Kuriyama K, Masuda N, Nishimura T, Kobayashi K, Tsubokura $\mathrm{T}$ and Nishimura $\mathrm{T}$ : Longitudinal practical measurement of skin color and moisture during and after breast-conserving therapy: influence of neoadjuvant systemic therapy. Jpn J Radiol 27: 309-315, 2009.

14 Yamazaki H, Yoshida K, Kobayashi K, Tsubokura T, Kodani N, Aibe N, Ikeno $\mathrm{H}$ and Nishimura T: Assessment of radiation dermatitis using objective analysis for patients with breast cancer treated with breast-conserving therapy: influence of body weight. Jpn J Radiol 30: 486-491, 2012.

15 Sasaoka M and Futami T: Dosimetric evaluation of whole breast radiotherapy using field-in-field technique in early-stage breast cancer. Int J Clin Oncol 16: 250-256, 2011.

16 Nakamura N, Takahashi O, Kamo M, Hatanaka S, Endo H, Mizuno N, Shikama N, Ogita M and Sekiguchi K: Effects of geometrical uncertainties on whole breast radiotherapy: a comparison of four different techniques. J Breast Cancer 17: 157-160, 2014.

17 Nagai A, Shibamoto Y, Yoshida M, Inoda K and Kikuchi Y: Intensity-modulated radiotherapy using two static ports of tomotherapy for breast cancer after conservative surgery: dosimetric comparison with other treatment methods and 3-year clinical results. J Radiat Res 58: 529-536, 2017.

18 Kestin LL, Sharpe MB, Frazier RC, Vicini FA, Yan D, Matter RC, Martinez AA and Wong JW: Intensity modulation to improve dose uniformity with tangential breast radiotherapy: initial clinical experience. Int J Radiat Oncol Biol Phys 48: 1559-1568, 2000.

19 Yoshida K, Yamazaki H, Takenaka T, Tanaka E, Kotsuma T, Fujita Y, Masuda N, Kuriyama K, Yoshida M and Nishimura T: Objective assessment of dermatitis following post-operative radiotherapy in patients with breast cancer treated with breastconserving treatment. Strahlenther Onkol 186: 621-629, 2010.

20 Sharma $\mathrm{N}$ and Purkayastha A: Factors affecting quality of life in breast cancer patients: a descriptive and cross-sectional study with review of literature. J Midlife Health 8: 75-83, 2017.

21 Hill-Kayser CE, Vachani C, Hampshire MK, Di Lullo GA and Metz JM: Cosmetic outcomes and complications reported by patients having undergone breast-conserving treatment. Int $\mathbf{J}$ Radiat Oncol Biol Phys 83: 839-844, 2012.

22 Schnur JB, Ouellette SC, Dilorenzo TA, Green S and Montgomery GH: A qualitative analysis of acute skin toxicity among breast cancer radiotherapy patients. Psychooncology 20: 260-268, 2011. 